\title{
Extreme genetic differences among populations of Gazella granti, Grant's gazelle, in Kenya
}

\author{
PETER ARCTANDER* ${ }^{*}$ PIETER W. KAT, RASHID A. AMAN $\uparrow \&$ HANS R. \\ SIEGISMUND \\ Department of Population Biology, University of Copenhagen, Universitetsparken 15, DK-2100 Copenhagen $\emptyset$, \\ Denmark, †Molecular Genetics Department, National Museums of Kenya, PO Box 40658, Nairobi, Kenya and \\ $\ddagger$ Arboretum, Royal Veterinary and Agricultural University, Kirkegårdsvej 3A, DK-2970 Hørsholm, Denmark
}

\begin{abstract}
Mitochondrial DNA (mtDNA) control region sequences from six Kenyan Grant's gazelle (Gazella granti) populations were highly divergent among locations. Neighbouring populations not separated by geographical or vegetational barriers exhibited a nucleotide sequence divergence of about 14 per cent. A similar level of divergence separates Grant's gazelles from a closely related species, the Soemmering's gazelle (G. soemmeringii). Nuclear microsatellite repeat number variation at two loci also indicated substantial population genetic differentiation. Despite high levels of sequence divergence, populations of Grant's gazelles were more closely related to each other than to Soemmering's and Thomson's gazelles (G. thomsoni) as measured by nucleotide sequence divergence at the mtDNA protein coding cytochrome $b$ gene and the nuclear $\alpha$-lactalbumin gene. This pattern of extensive differentiation is hypothesized to have resulted from recently established contacts between formerly allopatric populations.
\end{abstract}

Keywords: Gazella granti, microsatellites, mitochondrial DNA, population structure.

\section{Introduction}

Mitochondrial DNA has been widely used in genetic studies of population differentiation (Avise, et al., 1987). As mammal mtDNA evolves rapidly compared with nuclear DNA (Wilson et al., 1985), populations often show mtDNA variation that reflects aspects of the evolutionary history and ecology of the species (Avise, 1991). Partitioning of genetic variation has been observed to be minimal among populations of species in which gene flow is high and dispersal distances are large (Ball et al., 1988; Wayne et al., 1992), but can be significant when populations of poorly dispersing species are compared across geographical barriers (Avise, 1991). Earlier studies were almost entirely based on mtDNA restriction fragment length polymorphism analyses, but increasingly mtDNA nucleotide sequence data is being generated. This information has been mainly used to determine taxonomic relationships at the interspecific level (Irwin et al., 1991; Arnason et al., 1993; Bowen et al., 1993).

${ }^{*}$ Correspondence.
The most variable region of the mammal mtDNA genome is the control region (d-loop). Among humans, this region evolves three to five times faster than the rest of the mtDNA genome (Aquadro \& Greenberg, 1983), and apart from scattered sequence blocks conserved among taxa, the d-loop is characterized by rapid change in sequence and length (Saccone et al., 1991). This region is therefore well suited to population genetic analyses, and has proved useful in mapping differentiation among human populations (Horai \& Hayasaka, 1990; Vigilant et al., 1991; Piercy et al., 1993). Comparative data from other taxa are beginning to accumulate (Baker et al., 1993; Brown et al., 1993; Ron et al., 1993; Palsbøll et al., 1995, Arctander et al., 1996) but if nucleotide sequence analysis of the d-loop is to become important in the understanding of population genetic differentiation, an appreciation of the degree to which sequences can differ between populations is necessary.

Compared with small mammals and invertebrates, little is known about the population genetic structure of large terrestrial mammal species. This in part results from factors such as their relative scarcity, 
difficulty and cost involved in obtaining samples, and the degree to which underlying genetic patterns of differentiation have been altered by repeated bottlenecks, translocations and other anthropogenic disturbances. Relatively undisturbed populations of large mammals still exist in parts in Africa, however, and such populations provide unique opportunities to improve knowledge of the genetics of large mammals.

Grant's gazelles are distributed from northern Tanzania to southern Sudan and Ethiopia, and from the Kenya coast to Lake Victoria. They occur in lowland thornbush, savanna woodland, open plains and subdesert. The species is gregarious, territorial and migratory, and is relatively arid-adapted (Estes, 1991). Grant's gazelles exhibit considerable variability in size, horn shape and coat colour and on the basis of such differences a number of subspecies have been described (Kingdon, 1982). We report here that d-loop sequence variation among Grant's gazelle populations is extensive, and that such variation is not concordant with present-day barriers to migration.

\section{Materials and methods}

\section{Biological material}

Samples from Grant's gazelles were collected from six localities in Kenya: Masai Mara National Reserve, and Nairobi, Amboseli, Tsavo East, Samburu, and Sibiloi National Parks during 1991-92 (Fig. 1). Samples were obtained with the use of biopsy darts (Karesh et al., 1987) from free ranging individuals. In two cases samples of skin were obtained from dead individuals. Tissue was stored in liquid nitrogen in the field and at $-80^{\circ} \mathrm{C}$ in the laboratory.

\section{Amplification and sequencing}

DNA extraction followed standard procedures involving treatment of skin samples with SDS and proteinase $\mathrm{K}$, with subsequent phenol/chloroform extraction (Sambrook et al., 1989). A double-stranded polymerase chain reaction (PCR) product of the entire control region was obtained with the primers HH651 and HL15926 (Kocher et al., 1989). Singlestranded DNA from dideoxy termination sequencing was generated by unbalanced PCR of the doublestranded PCR product. The primers HL15926, HH16397 (5' -TTTCACGCGGCATGGTGATTAA$3^{\prime}$ ), and HH16168 (5'-GGTTGCTGGTTTCACGCGGCA-3') were used for single-stranded PCR as

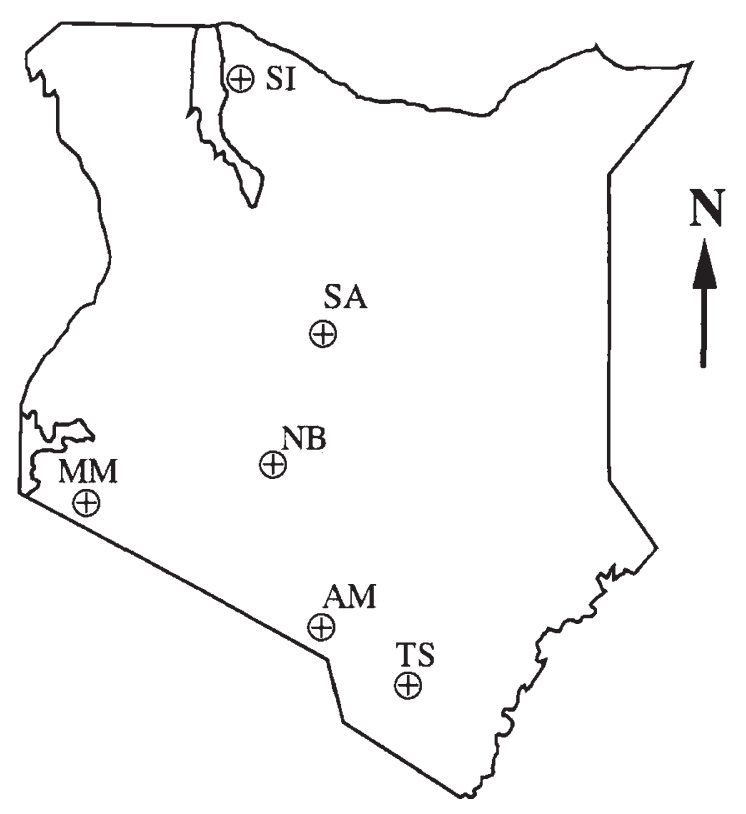

Fig. 1 Map of Kenya showing the sampling localities: MM: Masai Mara; AM: Amboseli; NB: Nairobi (two early samples were labelled NA); SA: Samburu; SI: Sibiloi; TS: Tsavo East.

well as sequencing: both strands were sequenced. PCR and sequencing followed standard procedures (Innis et al., 1990). A total of 44 individuals were sequenced for 371 base pairs (bp) within the left domain (Saccone et al., 1991) of the d-loop immediately downstream from tRNA ${ }^{\mathrm{PRO}}$.

For amplification and sequencing of $\alpha$-lactalbumin the primers LacI (5'-CTCACTGTCACAGGAGATGT-3') and LacII (5'-CCAAAATGATGTCCTTTGTC-3') (D. Irwin, personal communication) were used to sequence 473 bp covering intron I, 29 bp exon I and 115 bp exon II (Vilotte et al., 1987). No signs of heterozygosity were detected. The 306 bp cytochrome b (cyt $b$ ) sequence was obtained using the primers HL14841 and HH 15149 (Kocher et al., 1989). Sequences of $\alpha$-lactalbumin and cyt $b$ were readily aligned with those of the cow (Anderson et al., 1982; Fries et al., 1993).

\section{Microsatellites}

Two microsatellite loci were analysed. BOLADRBP2 (BOLA2) is within MHC class II beta pseudogene 2 and BOVPRL $(P R L)$ is within Prolactin. Primers for PCR (Fries et al., 1994) designed for the domestic cow, were kindly provided by Dan Bradley, Department of Genetics, University of Dublin, Ireland. 


\section{Analysis of sequence data}

Nucleotide diversity (Nei, 1987) was used to estimate genetic diversity within and between populations. The sequence statistic $K_{\mathrm{ST}}$ (Hudson et al., 1992), which determines the fraction of sequence divergence accounted for by population differentiation, was used to test for population subdivision. The approximate statistical significance of observed $K_{\mathrm{ST}}$ values was estimated by Monte Carlo simulations where individuals were sampled without replacement and randomly assigned to populations. The distribution of $K_{\mathrm{ST}}$ values over 1000 simulations then permits an assessment of statistical significance: large observed values of $K_{\mathrm{ST}}$ have small probability values (Hudson et al., 1992).

Sequence alignment was performed by eye. Insertions/deletions were introduced trying to minimize transversions. A phylogenetic tree of d-loop sequences was estimated with the program FITCH from maximum likelihood distances among the sequences generated with DNADIST (Felsenstein, 1993). For DNADIST we used a transition/transversion ratio of 14 and the empirical frequencies of the bases. Bootstrap samples (Felstenstein 1985) were generated with the program SEQBOOT, from which distance matrices were estimated by DNADIST. The trees estimated by FITCH were analysed with CONSENSE (Felsenstein 1993).

Sequences were deposited in GenBank under the accession numbers L14021 to L14060.

\section{Analysis of microsatellite data}

The observed genotypic distributions at the microsatellite loci were compared with the expected Hardy-Weinberg proportions using the method of Guo \& Thomson (1992). The significance level was found as the fraction of 1000 Monte Carlo permutations of individual allele combinations that resulted in genotypic probabilities as large as or smaller than the observed ones.

Gene diversity at each locus was estimated according to Nei (1987) and averaged across the two loci.

Population subdivision was quantified with $F$-statistics according to Weir \& Cockerham (1984). Standard deviations of the parameters were found by jackknifing across populations.

The allele frequency distributions at the microsatellite loci were compared between populations also by Monte Carlo permutation tests, and $\chi^{2}$ values were estimated in each permutation and compared with the observed $\chi^{2}$ value (Roff \& Bentzen, 1989).
The significance levels at the two loci were combined using Fisher's method for independent tests (Manly, 1985).

\section{Results}

\section{Sequence data}

The 371 bp sequenced of the d-loop showed extensive variation at 142 variable sites, resulting in 40 different d-loop sequences among the 44 Grant's gazelle individuals examined. Four sequences were found in two copies, which always were collected in the same population (Table 1). The five populations (Sibiloi is included in the Samburu population, see below) differ in the level of nucleotide diversity. The lowest diversity (1.94 per cent) is found in the divergent Tsavo population, whereas a threefold higher value (6.2 per cent) is found in the population from Amboseli. The other three populations have intermediate diversities (Table 2).

The phylogenetic relationships among the d-loop sequences (Fig. 2) indicate that the samples fall into three major groups: Tsavo East, Samburu/Sibiloi and Masai Mara/Nairobi/Amboseli. The partitioning into these groups is supported by high bootstrap values (Fig. 2). The samples from Tsavo are the most divergent. The sum of the branch lengths connecting this group with the other two groups amounts to about 14 per cent expected substitutions per base. The Samburu/Sibiloi and Masai Mara/Nairobi/Amboseli groups are separated by branches with a total length of 7 per cent expected substitutions per base (Fig. 2). Similar values are found by estimating the net nucleotide differences between populations (Table 2). The net nucleotide differences between the samples from Masai Mara, Nairobi and Amboseli are all less than 1 per cent (Table 2).

Inspection of the phylogenetic tree (Fig. 2) reveals that the samples from Masai Mara are clusterd in a single monophyletic group plus two interspersed among sequences from Nairobi and Amboseli, suggesting that the Masai Mara population is differentiated from the other two. There is no evidence of a grouping according to geography for sequences from Amboseli and Nairobi (Fig. 2).

In the test for population differentiation based on the method of Hudson et al. (1992) a preliminary analysis indicated that the two individuals from Sibiloi did not differ significantly from the samples collected in Samburu $(P>0.82)$, but differed significantly from the samples from Masai Mara $(P<0.01)$, Nairobi $(P<0.02)$, Tsavo $(P<0.02)$ and were as different as possible (given the small sample size) in 
Table 1 D-loop sequences from 44 Grant's gazelles from six different localities

\begin{tabular}{|c|c|}
\hline \multirow[t]{2}{*}{ Sequence } & Position \\
\hline & $\begin{array}{l}1111111111111111111111112222222222222222222222222222222222222 \\
2224578800111122333334444444599901122222222233333344444444445555556666 \\
2382836707234536045780123456126727901234567813678901234567890234560135\end{array}$ \\
\hline MM1 & ATGCATCTCTACACTGTTGGAGA- - - СТATTGCCTATATCACGCACACACCAAGTACAATTGTCTGCCC \\
\hline 12 & 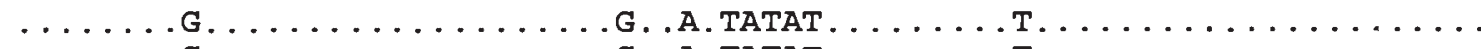 \\
\hline & $\ldots \ldots \ldots \ldots \ldots \ldots$. .А.ТАТАT. . . . . . . . . . \\
\hline 14 & . G. .A.............. \\
\hline 15 -7 & $\ldots \ldots \ldots \ldots \ldots \ldots$ А........ \\
\hline $16^{-}$ & 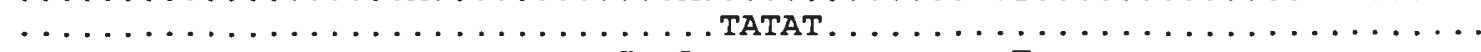 \\
\hline 18 & 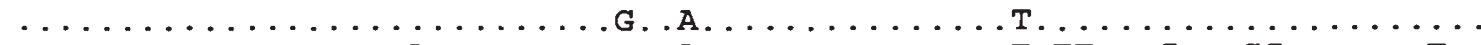 \\
\hline & $\ldots \ldots \ldots \ldots \ldots$. . . . . . . . . . . . . \\
\hline MM10 & 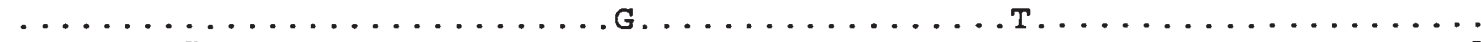 \\
\hline N) & 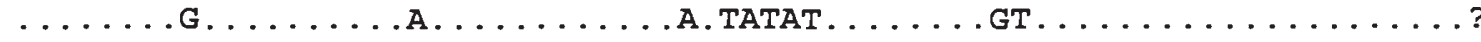 \\
\hline & А.......... \\
\hline & ..... А.ТАТАТ..ТА..Т.Т...... \\
\hline & ............. ААТАT. ............. \\
\hline 35 & .... ТАТАТ............... \\
\hline & . А. . . . . . А.ТАТАТ. . . . . . ТT. .С.T.GC. \\
\hline & ............... . \\
\hline NB8 & .А. \\
\hline AM2 & $\ldots \ldots \ldots \ldots$. \\
\hline AM3 & ..... ТАТАT. \\
\hline AM4 & 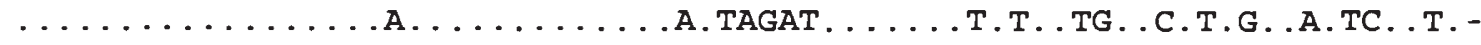 \\
\hline AM5 & . . А. ТАТАТ. . . . . . . . . . . \\
\hline SA1 & .G.C.TTACAT.T. .AT.T. .GT.G...G....САCT.AT. \\
\hline & . . . .TTACAT.T. .AT.T. .G.........ACT.AT. \\
\hline & . GC. .TTACAT.T..AT.T..G..G. \\
\hline SA4_7 & 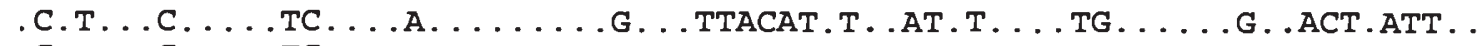 \\
\hline SA5 & 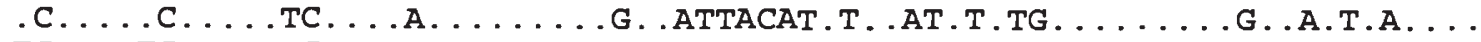 \\
\hline SA8 & .G. .АTTACAT.T. .АT-T. .G.TG.A.G. . .САCT.АTT. \\
\hline SA9 & . .G. .АTTACAT.T. .АT-T. .G.TG.A.G. . . САCT. АTT. \\
\hline SA10 & ..G...TTACAT.T. .AT.T. .GT.G...G....СACT.AT. \\
\hline SII & . .G. .АTTACAT.T. .АT-T. .GTTG.A.G. . . САCT. АTT. \\
\hline SI & 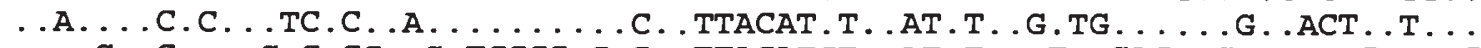 \\
\hline & 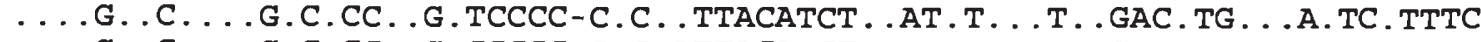 \\
\hline TS2 & ...G..C....G.C.CC. .G.CCCCC-C.C. ATTACATCT. .AT.T.T.T. .GAC.TG. . A.TC.TTT \\
\hline TS3 & 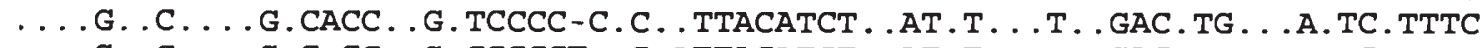 \\
\hline TS4 & 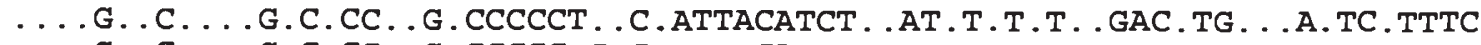 \\
\hline TS5 & .G.C.CC..G-CCCCC-C.C..TTACATCT. .АT.T.T.T..GAC.TG. \\
\hline TS6 & .G.C.CC..G-CССCC-C.... TTACATCT..АT.T.T.T..GAC.TG. . \\
\hline TS7_-9 & .G.C.CC. .G-TCCCC-C.C. . TTACATCT. .AT.T. . T. .GAC.TG. . A.TC.TTTC \\
\hline & .G.C.CC. .G-TCCCC-C.C. .TTACATCT. .AT.T. .T. . GAC.TG. . A.TC.TTTC \\
\hline & .G.C.CC. .G-CCCCC-C... .TTACATCT. .АT.T.T.T. .GAC.TG...A.TC.TTT \\
\hline
\end{tabular}

a comparison to the four individuals from Amboseli $(P<0.07)$. Sibiloi individuals were therefore included in the Samburu sample.

A test for homogeneity of all five populations reveals that $K_{\mathrm{ST}}=0.661$, which is significant at the 0.001 level. Thus, the largest part of the total nucleotide diversity for all populations (0.109) results from partitioning of the diversity among populations. The rejection of the hypothesis of homogeneity is not surprising considering the large differences among sequences in the three major groups (Fig. 2). The population structure is further analysed by homogeneity tests of the populations in pairs (Table 2). The tests should be interpreted with caution because of inherent correlations and because of problems arising from multiple comparisons. The results of tests involving populations from Tsavo or Samburu/Sibiloi are clear. Except for two 
Table 1 Continued

\begin{tabular}{|c|c|}
\hline \multirow[t]{2}{*}{ Sequence } & Position \\
\hline & $\begin{array}{l}22222222222222222222222222233333333333333333333333333333333333333333333 \\
66677777777788888899999999900000000011111222222233334445555555556666677 \\
78902345678901235901345678901235678902389245678903790371234567890128901\end{array}$ \\
\hline 11 & T-CGACCTAGTTCTATATACCAAACA-GAACTGGTACCAAGC--- - - GAGTAAG-CG \\
\hline M2 & 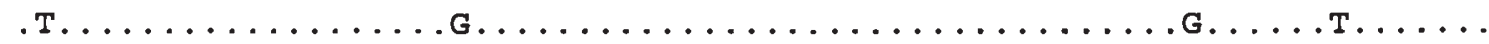 \\
\hline MM3 & 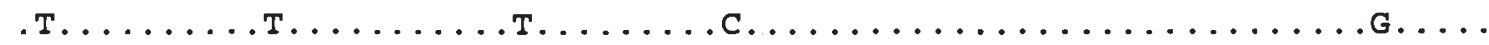 \\
\hline MM4 & 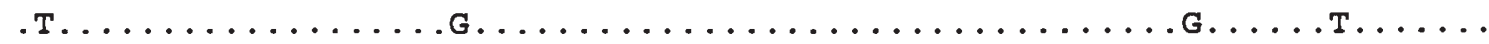 \\
\hline M5_ 7 & 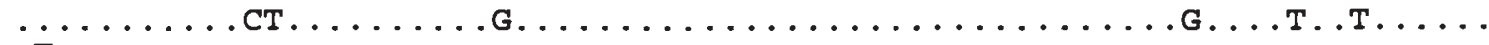 \\
\hline $\mathrm{M}^{-}$ & $\ldots \ldots \ldots \ldots \ldots \ldots \ldots \ldots \ldots \ldots \ldots \ldots \ldots \ldots \ldots \ldots \ldots \ldots \ldots \ldots \ldots \ldots$ \\
\hline M8 & 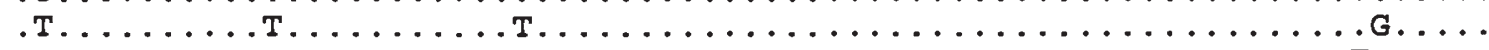 \\
\hline MM9 & 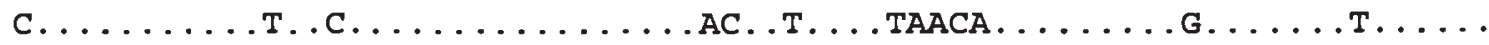 \\
\hline MM10 & 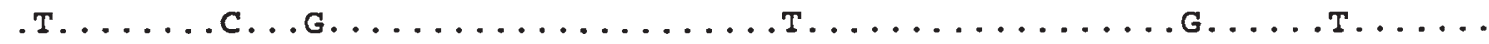 \\
\hline IAI & 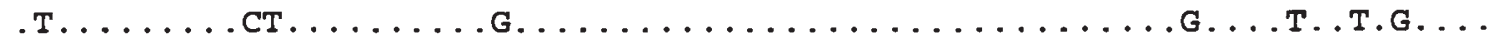 \\
\hline 2 & 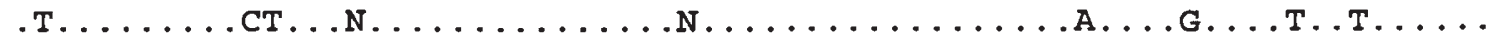 \\
\hline NB3 & $\ldots \ldots \ldots \ldots$............... \\
\hline NB4 & 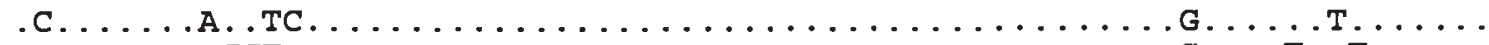 \\
\hline 5 & 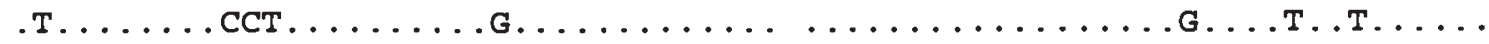 \\
\hline IB6 & 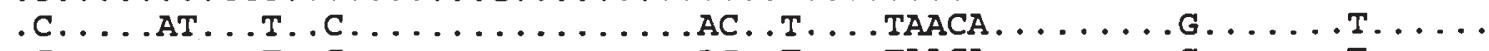 \\
\hline BB7 & $\ldots \ldots \ldots$.... . . . . TAACA ............... \\
\hline IB8 & $\ldots \ldots \ldots \ldots \ldots \ldots \ldots \ldots \ldots \ldots \ldots \ldots \ldots \ldots \ldots \ldots \ldots \ldots \ldots$ \\
\hline M2 & 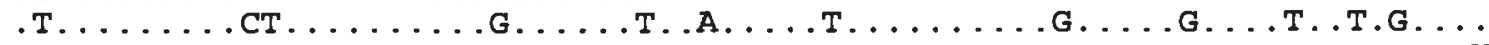 \\
\hline M3 & 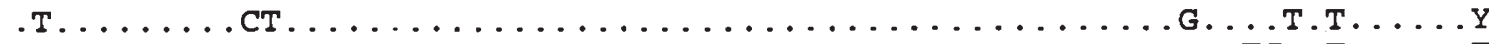 \\
\hline M4 & 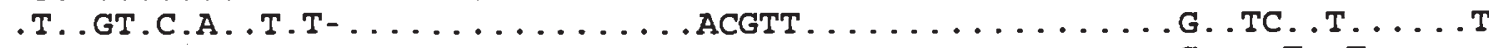 \\
\hline AM5 & 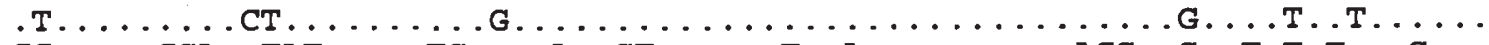 \\
\hline 1 & 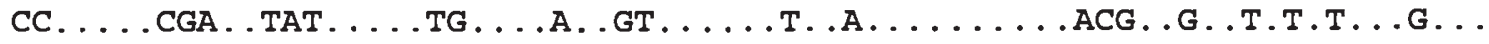 \\
\hline SA2_6 & 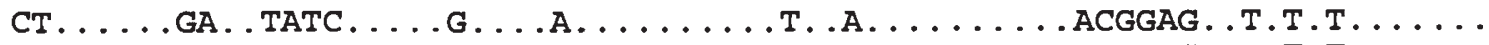 \\
\hline A3 & 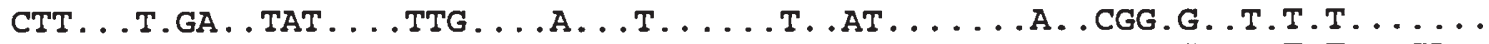 \\
\hline SA4_ 7 & $\ldots$... . . .......... CG.AG. . .T.T...GA. \\
\hline & 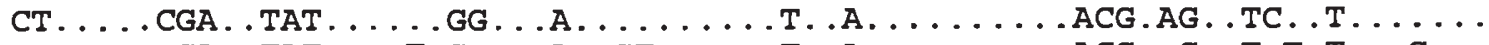 \\
\hline & 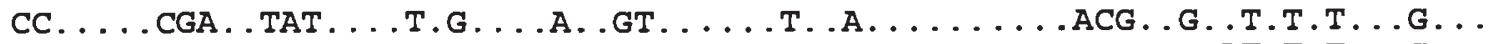 \\
\hline A9 & 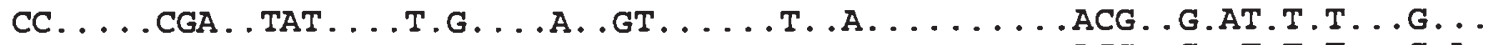 \\
\hline 110 & 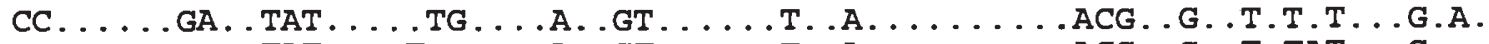 \\
\hline & . . . . ......... ACG..G..T.TAT..... \\
\hline SI2 & 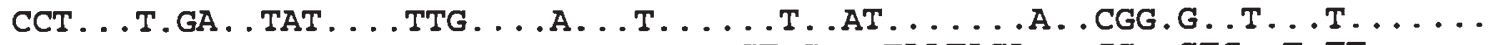 \\
\hline & 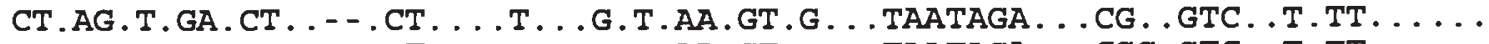 \\
\hline & 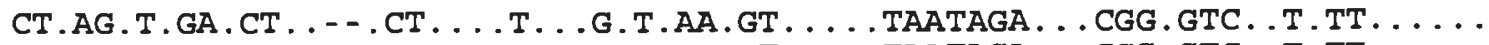 \\
\hline & 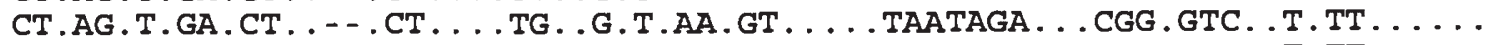 \\
\hline TS & 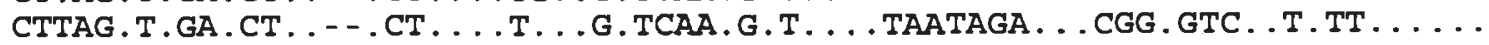 \\
\hline TS5 & 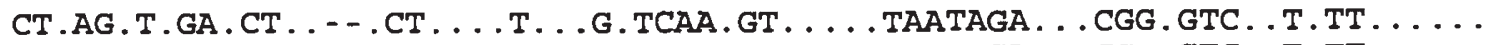 \\
\hline TS6 & 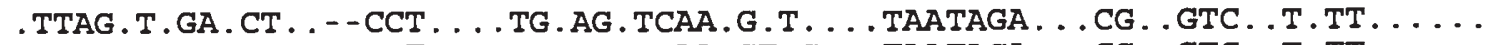 \\
\hline TS7_9 & 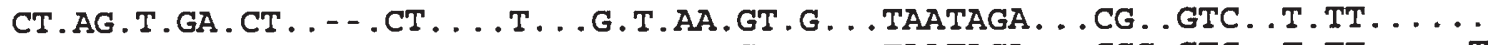 \\
\hline & 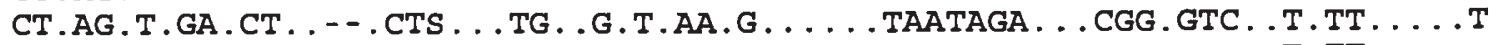 \\
\hline S10 & 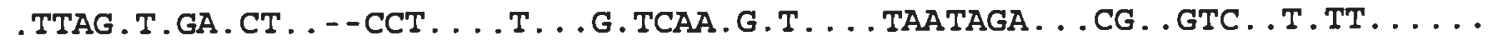 \\
\hline
\end{tabular}

Abbreviations as in Fig. 1. Only the 142 variable sites are shown. Sequences found in more than one individual carry the numbers of the individuals. Dots designate equality with MM1, -insertion/deletion, Y either T or C, S is C or G, and ? an undecided base.

tests, which were significant at the 0.2 per cent level, none of the other permutation tests resulted in $K_{\mathrm{ST}}$-values exceeding the observed ones. This agrees well with the phylogenetic trees in Fig. 2. The picture for the remaining three populations is less clear. Although the populations from Masai Mara,
Nairobi and Amboseli are grouped together in the phylogenetic tree, a test for homogeneity (Hudson et $a l .$, 1992) of the d-loop variation for all three populations was rejected $(P<0.01)$. This supports the previous findings that apart from two Masai Mara genotypes which cluster with gazelles from Nairobi 
Table 2 Sequence statistics for Grant's gazelles based on the $371 \mathrm{bp}$ d-loop sequence, with all insertions/-deletions omitted

\begin{tabular}{lcccccc}
\hline & & \multicolumn{5}{c}{ Location } \\
\cline { 3 - 7 } Location & $\begin{array}{c}\text { Sample } \\
\text { size }\end{array}$ & MM & NA/NB & AM & SA & TS \\
\hline MM & 10 & $\mathbf{0 . 0 3 0 9}$ & 0.0088 & 0.0034 & 0.0930 & 0.1420 \\
NA/NB & 8 & 0.002 & $\mathbf{0 . 0 3 7 3}$ & 0.0035 & 0.0888 & 0.1282 \\
AM & 4 & 0.156 & 0.870 & $\mathbf{0 . 0 6 1 6}$ & 0.0784 & 0.1176 \\
SA & 12 & 0.000 & 0.000 & 0.002 & $\mathbf{0 . 0 4 7 8}$ & 0.1214 \\
TS & 10 & 0.000 & 0.000 & 0.002 & 0.000 & $\mathbf{0 . 0 1 9 4}$ \\
\hline
\end{tabular}

Abbreviations as in Fig. 1. Diagonal: Nei's nucleotide diversity within populations. Upper right: net nucleotide differences between populations.

Lower left: significance levels for pairwise tests for geographical subdivision.

and Amboseli, all other Masai Mara gazelles cluster together. A pairwise comparison of the three populations reveals only a single significance at the 5 per cent level (Table 2). The populations from Masai Mara and Nairobi differ significantly, indicating the existence of separate populations linked by limited gene flow across a geographical feature, the eastern African Rift Valley.

The high level of d-loop sequence divergence of gazelles from Tsavo raised the question of how large this intraspecific differentiations relative to interspecific differences. For this purpose the sequences of individuals from Masai Mara, Samburu and Sibiloi were compared with d-loop sequences from the closely related Soemmering's gazelle $(G$. soemmeringii) and Thomson's gazelle ( $G$. thomsoni) (Table 3). The divergence from Soemmering's gazelle is of the same order as the intraspecific differentiation, whereas Thomson's gazelle has a somewhat raised level of transitions and a threefold higher level of transversions. It might therefore be suggested that the populations are in the process of speciation. To address this question, we analysed $306 \mathrm{bp}$ of the mtDNA cyt $b$ sequence, and $473 \mathrm{bp}$ of the nuclear $\alpha$-lactalbumin sequence from the three Grant's gazelle groups and compared these sequences with those from Soemmering's gazelle and Thomson's gazelle (Table 4). When cyt $b$ sequences were compared, Soemmering's gazelle showed a twofold increase relative to intraspecific divergence in Grant's gazelle and Thomson's gazalle showed a fourfold increase (Table 4). A pattern similar to cyt $b$, but with fewer substitutions, is revealed by the more slowly evolving nuclear $\alpha$-lactalbumin gene.

\section{Restriction site polymorphisms of cyt $\mathrm{b}$ amplifications}

The cyt $b$ fragment that was used for interspecific comparisons was amplified for all 44 Grant's gazelles. Subsequent digestion with restriction enzymes $A f l \mathrm{III}$ and $H$ infI indicates an $\mathrm{A}$ at position 14801 (numbered according to Anderson et al., 1982) for all individuals from Tsavo, whereas all other indivdiuals have a $G$ at this position. At position 14747, gazelles from Tsavo, Samburu and Sibiloi have a $\mathrm{C}$ whereas animals from the other populations sampled have a $\mathrm{T}$.

\section{Microsatellite variation}

There are no suggestions of deviations from random mating within the populations. All genotypic distributions at the two microsatellite loci are in accordance with the expected Hardy-Weinberg proportions in all five populations (Table 5), which is also reflected in $F_{\text {IS }}$-values that do not differ significantly from zero (Table 6).

The number of observed alleles at the two microsatellite loci is high considering the sample sizes (Table 5). A total of seven and eight alleles are observed at the BOLA2 and PRL loci, respectively. This is also reflected in a high gene diversity, which ranged from 0.474 in Masai Mara to 0.741 in Samburu/Sibiloi (Table 5). The genetic differentiation at the microsatellite loci is lower than that which has been observed for the d-loop sequence variation. Table 6 presents the $F$-statistics for the two loci. The part of the total diversity of 0.728 , which is attributable to differentiation among the populations $\left(F_{\mathrm{ST}}\right)$, amounts to one-quarter to

(c) The Genetical Society of Great Britain, Heredity, 76, 465-475. 
Fig. 2 Phylogenetic relationship of the sequences from Grant's gazelles. At the major branches two values are inserted: the upper is the distance measured as the expected number of substitutions per base; the lower is the frequency that a group was found to be monophyletic for 200 bootstrapped samples of the sequences.

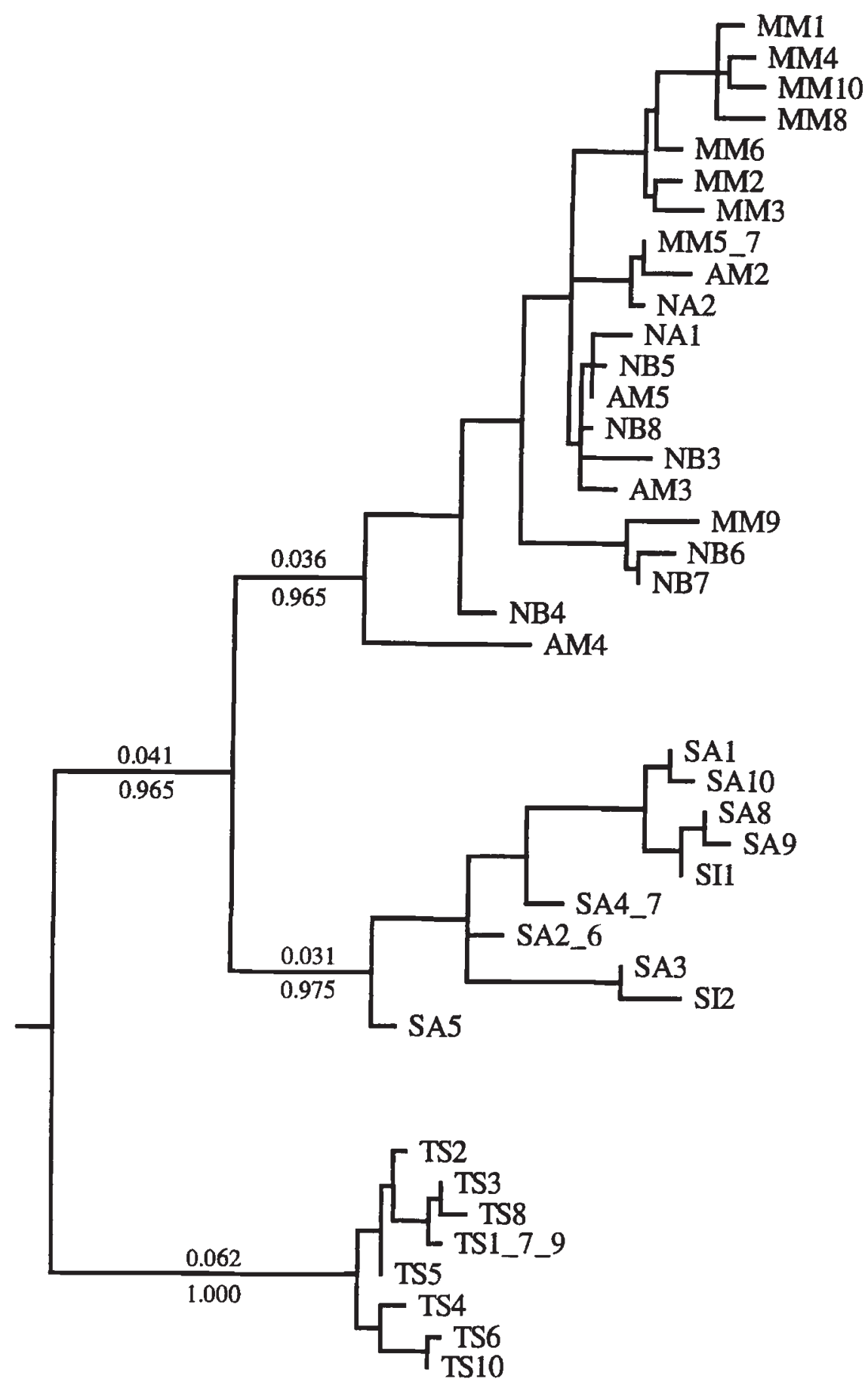

one-third of the nucleotide differentiation at the d-loop. The $F_{\mathrm{ST}}$ value differs from 0 (it is larger than two times the standard deviation, Table 6), indicating significant differentiation among the populations. This is supported by the occurrence of population-specific alleles. Examples of unique alleles with high frequencies are allele 2 of $B O L A 2$ and allele 2 of $P R L$ in the Samburu population, and allele 3 of $P R L$ in the Nairobi population. Common alleles that are missing in single populations are 
Table 3 Pairwise comparison of substitutions in d-loop sequences between representatives from the three major groups of Grant's gazelles, Soemmering's gazelle and Thomson's gazelle

\begin{tabular}{lrrrrr}
\hline & \multicolumn{5}{c}{ Sequence } \\
\cline { 2 - 6 } Sequence & 1 & 2 & 3 & 4 & 5 \\
\hline 1. Grant's MM4 & & 10 & 8 & 10 & 37 \\
2. Grant's SA1 & 45 & & 7 & 11 & 33 \\
3. Grant's TS1 & 56 & 51 & & 7 & 35 \\
4. Soemmering's & 54 & 60 & 46 & & 28 \\
5. Thomson's & 78 & 77 & 77 & 77 & \\
\hline
\end{tabular}

Transversions above diagonal, transitions below.

Abbreviations as in Fig. 1.
Table 4 Pairwise comparison of substitutions in cyt $b$ sequences (above diagonal) between representatives from the three major groups of Grant's gazelles, Soemmering's gazelle and Thomson's gazelle

\begin{tabular}{lrrrrr}
\hline & \multicolumn{5}{c}{ Sequence } \\
\cline { 2 - 6 } Sequence & 1 & 2 & 3 & 4 & 5 \\
\hline 1. Grant's MM4 & & 0 & 0 & 1 & 7 \\
2. Grant's SA1 & 6 & & 0 & 1 & 7 \\
3. Grant's TS1 & 9 & 5 & & 1 & 7 \\
4. Soemmering's & 16 & 12 & 13 & & 8 \\
5. Thomson's & 30 & 26 & 27 & 28 & \\
\hline
\end{tabular}

Abbreviations as in Fig. 1.

Table 5 Allele frequencies for Grant's gazelles of two microsatellite loci:

$B O L A 2$ and $P R L$

\begin{tabular}{|c|c|c|c|c|c|c|}
\hline \multirow[b]{2}{*}{ Locus } & \multirow[b]{2}{*}{ Allele } & \multicolumn{5}{|c|}{ Location } \\
\hline & & MM & NA/NB & $\mathrm{AM}$ & SA & TS \\
\hline \multirow[t]{10}{*}{$B O L A 2$} & 1 & 0 & 0 & 0 & 0.04 & 0 \\
\hline & 2 & 0 & 0 & 0 & 0.17 & 0 \\
\hline & 3 & 0.10 & 0.06 & 0.25 & 0.21 & 0 \\
\hline & 4 & 0 & 0.38 & 0.38 & 0.46 & 0.40 \\
\hline & 5 & 0 & 0.06 & 0 & 0 & 0.05 \\
\hline & 6 & 0.90 & 0.50 & 0.38 & 0.04 & 0.55 \\
\hline & 7 & 0 & 0 & 0 & 0.08 & 0 \\
\hline & $H_{\mathrm{e}}$ & 0.188 & 0.631 & 0.776 & 0.749 & 0.565 \\
\hline & $n$ & 10 & & & & \\
\hline & $P$ & 1.000 & 0.473 & 0.363 & 0.101 & 1.000 \\
\hline \multirow[t]{12}{*}{$P R L$} & 1 & 0 & 0 & 0 & 0 & 0.05 \\
\hline & 2 & 0 & 0 & 0 & 0.29 & 0 \\
\hline & 3 & 0 & 0.30 & 0 & 0 & 0 \\
\hline & 4 & 0.20 & 0.40 & 0.38 & 0.17 & 0.60 \\
\hline & 5 & 0.15 & 0.30 & 0.63 & 0.42 & 0 \\
\hline & 6 & 0.40 & 0 & 0 & 0.08 & 0.35 \\
\hline & 7 & 0.20 & 0 & 0 & 0.04 & 0 \\
\hline & 8 & 0.05 & 0 & 0 & 0 & 0 \\
\hline & $H_{\mathrm{e}}$ & 0.759 & 0.716 & 0.574 & 0.733 & 0.549 \\
\hline & $n$ & 10 & & 4 & 12 & 10 \\
\hline & $P$ & 0.836 & 0.199 & 0.414 & 0.930 & 0.680 \\
\hline & Ave $H_{\mathrm{e}}$ & 0.474 & 0.674 & 0.675 & 0.741 & 0.557 \\
\hline
\end{tabular}

$n$ is the number of individuals analyzed. $P$ is the significance level for deviations from Hardy-Weinberg proportions. $H_{\mathrm{e}}$ is the gene diversity. Other

abbreviations as in Fig. 1. 
Table $6 F$-statistics and their standard errors at the microsatellite loci analysed for Grant's gazelles

\begin{tabular}{lrc}
\hline Locus & \multicolumn{1}{c}{$F_{\mathrm{IS}}$} & \multicolumn{1}{c}{$F_{\mathrm{ST}}$} \\
\hline BOLA2 & $0.168 \pm 0.129$ & $0.243 \pm 0.159$ \\
PRL & $-0.021 \pm 0.130$ & $0.166 \pm 0.041$ \\
Combined estimate & $0.069 \pm 0.103$ & $0.199 \pm 0.067$ \\
\hline
\end{tabular}

Table 7 Significance levels for pairwise homogeneity tests of allele numbers among populations of Grant's gazelles with the test statistics summed across the loci

\begin{tabular}{lccccc}
\hline & \multicolumn{5}{c}{ Location } \\
\cline { 2 - 6 } & MM & NA/NB & AM & SA & TS \\
\hline NA/NB & 0.000 & & & & \\
AM & 0.000 & 0.106 & & & \\
SA & 0.000 & 0.000 & 0.039 & & \\
TS & 0.000 & 0.001 & 0.001 & 0.000 & \\
\hline
\end{tabular}

allele 3 of $B O L A 2$ and allele 5 of $P R L$ in the Tsavo population and allele 4 of $B O L A 2$ in the Masai Mara population.

The hypothesis of low gene flow among the populations is corroborated by the permutation test of Roff \& Bentzen (1989) for homogeneity among all five populations. They are significant at the 0.001 level at both loci. The tests for pairwise homogeneity (Table 7) show similar results to the sequence-based tests (Table 2). Only the comparison of Amboseli and Nairobi is nonsignificant at the 5 per cent level, suggesting a general low level of gene flow among the populations.

\section{Discussion}

Grant's gazelles can disperse over large distances: although the Samburu and Sibiloi sampling localities are more than $450 \mathrm{~km}$ apart, the gazelles in these populations are not genetically different. In constrast, samples from Tsavo East and Amboseli were collected only $180 \mathrm{~km}$ apart, but no evidence of gene flow between these populations was apparent.

The d-loop sequence divergence is greatest when gazelles from Tsavo East are compared with those of the other localities. The amount of divergence, 12-14 per cent, is to our knowledge among the highest level of intraspecific nucleotide sequence divergence reported to date. Similar studies on waterbuck (Kobus ellipsiprymnus), wildebeest
(Connochaetes taurinus) and impala (Aepyceros melampus) populations sampled from the same areas in Kenya revealed divergences on the order of 0.2-1.4 per cent (Arctander et al., 1996). Humans differ from each other by values in the range of 0.1-3.6 per cent (Horai \& Hayasaka, 1990), among white sturgeons the mean value between populations is 2.3 per cent (Brown et al., 1993), and ranging from 0.8 per cent to 2.9 per cent within different feeding aggregations of North Atlantic humpback whales (Palsbøll et al., 1995). High levels of intraspecific divergence have also been reported for the chimpanzee (Pan troglodytes; Morin et al., 1994). The net nucleotide distance between the subspecies $P$. $t$. schweinfurthii and $P$. $t$. troglodytes was 8.9 per cent, which is lower than the results for Grant's gazelle. The two above-mentioned subspecies had a net nucleotide distance of 32.4 per cent to the third subspecies, $P$. $t$. verus, a value that is substantially larger than the differences observed for Grant's gazelle. Unlike Grant's gazelle, the intraspecific divergences among subspecies of the chimpanzee are still smaller than the distance of 54-62 per cent to their closest relative, the bonobo ( $P$. paniscus). The high value among the subspecies of the chimpanzee could suggest that the taxonomic position of the subspecies $P$. $t$. verus should be raised to full species if the results were supported by similar findings at nuclear loci (Morin et al., 1994).

The estimate of genetic differentiation among populations was three to four times higher for the d-loop sequences than for the microsatellite loci. This result could arise from differences in effective population size $\left(N_{\mathrm{e}}\right)$ of mitochondrial and nuclear genes, but the actual difference in $N_{\mathrm{e}}$ is unknown because of insufficient knowledge of the mating system. Female gazelles could also be more philopatric than males. Another reason for the observed difference in genetic differentiation could be different modes of evolution of the d-loop and the microsatellites. The latter could be more influenced by back mutations, which results in a decreased level of differentiation.

The high level of d-loop sequence divergence among Grant's gazelle populations is comparable to that separating Grant's gazelles from a related species, the Soemmering's gazelle. The three major groups of Grant's gazelles differed from each other by approximately 6 per cent of cyt $b$ third positions, which amounts to about half the difference from Soemmerings gazelle. Therefore, their differentiation is probably about half as old as that separating them from Soemmerings's gazelles. Estimates based on the assumption of 1 per cent third position diver- 
gence per 50000 years (Irwin et al., 1991) indicate a common population ancestry about 300000 years ago.

The observed genetic differences among the Grant's gazelle populations could have arisen parapatrically or allopatrically. Parapatric differentiation would in our opinion require a defined ecotone with markedly different selective regimes on either side of the boundary. The morphological characters used to segregate the different subspecies, such as horn shape and slight differences in coat colour (Kingdon, 1982), are not indicative of ecological separation. All populations inhabit arid to semiarid open savanna, and no geographical or ecological barrier or gradient is apparent: Grant's gazelles occur widely in areas between sampling locations, especially between Tsavo East and Amboseli. A more likely explanation is that secondary contact has been established between populations that have until recently been allopatric. The differentiation may have evolved during repeated expansion and contraction of arid habitats during the late Pleistocene (Hamilton, 1982) that probably isolated populations. The inferred lack of interbreeding between the three major groups could be caused by chromosomal differences, a phenomenon commonly observed among gazelles (Benirschke et al., 1980) and which may contribute to reproductive barriers.

Despite their dispersal capabilities, large mammal species can thus exhibit surprising levels of divergence among populations even in the absence of barriers to gene flow. Such barriers might have existed historically and not be apparent today, especially if they were linked to palaeoclimates. These results have practical consequences for conservation biology as they emphasize the need for preservation of a diverse array of populations. In addition, a thorough knowledge of patterns of differentiation among African wildlife populations will be required to conserve adequately and manage this resource.

\section{Acknowledgements}

The Kenya Wildlife Service, the Narok County Council and the wardens in Masai Mara National Reserve, and Nairobi, Amboseli, Tsavo East and Samburu National Parks are thanked for sampling permissions and support; Bent Christensen and Jon Fjeldså for ideas and discussion; and Pia Friis and Christina Færch-Jensen for technical assistence. DNA and cyt $b$ sequence from Soemmering's gazelle (G. s. berberana from Somalia) were provided by Pim Rebholz, Insitute of Zoology, the Zoological
Society of London. The study was supported the Danish International Development Agency (DANIDA), the Carlsberg Foundation and the Danish Natural Science Research Council.

\section{References}

ANDERSON, S., DE BRUIJN, M. H. L., COULSON, A. R. EPERON, I. C. SANGer, F. AND YOUNG I. G. 1982. Complete sequence of bovine mitochondrial DNA. Conserved features of the mammalian mitochondrial genome. $J$. Mol. Biol., 156, 683-717.

AQUADRO, C. F. AND GREENBERG, B. D. 1983. Human mitochondrial DNA variation and evolution: analysis of nucleotide sequences for seven individuals. Genetics, 103, 287-312.

ARCTANDER, P., KAT, P. W., SIMONSEN, B. T. AND SIEGISMUND, H. R. 1996. Population genetics of Kenyan impalas - consequences for conservation. In: Wayne, R. K. and Smith, T. B. (eds) Molecular Genetics in Conservation. Oxford University Press, Oxford.

ARNASON, U., GULLBERG, A., JOHNSSON, A. E. AND LEDJE, C. 1993. The nucleotide sequence of the mitochondrial DNA molecule of the grey seal, Halichoerus grypus, and a comparison with mitochondrial sequences of other true seals. J. Mol. Evol., 37, 323-330.

AVISE, J. C. 1991. Ten unorthodox perspectives on evolution prompted by comparative population genetic findings on mitocondrial DNA. Ann. Rev. Genet., 25, 45-69.

AVISE, J. C., ARNOLD, J., BALL, R. M., BERMINGHAM, E., LAMB, T., NEIGEL, J. E., REEB, C. A. AND SAUNDERS, N. C. 1987. Intraspecific phylogeography: the mitochondrial DNA bridge between population genetics and systematics. Ann. Rev. Ecol. Syst., 18, 489-522.

BAKER, C. S., PERRY, A., BANISTER, J. L., WEINRICH, M. T., ABERNETHY, R. B., CALAMBODKIS, J., LIEN, I., LAMBERSTEN, R. H., URBAN-RAMIREZ, J., VASQUEZ, O., CLAPHAM, P. J., Alling, A., O'BRIEN, S. J. AND PALUMBI, S. R. 1993. Abundant mitochondrial DNA variation and worldwide population structure in humpback whales. Proc. Natl. Acad. Sci. U.S.A., 90, 8239-8243.

BALL, R. M., FREEMAN, S., JAMES, F. C., BERMINGHAM, F. AND AVISE, J. C. 1988. Phylogeographic population structure of red-winged blackbirds assessed by mitochondrial DNA. Proc. Natl. Acad. Sci. U.S.A., 85, $1558-1562$.

BENIRSCHKE, K., LASLEY, B. AND RYDER, O. 1980. The technology of captive propagation. In: Soulé, M. E. and Wilcox, B. A. (eds) Conservation Biology, An Evolutionary-Ecological Perspective, pp. 225-242. Sinauer Associates, Sunderland, MA.

BOWEN, B. W., NELSON, W. S. AND AVISE, J. C. 1993. A molecular phylogeny for marine turtles: trait mapping, rate assessment, and conservation relevance. Proc. Natl. Acad. Sci. U.S.A., 90, 5574-5577.

BROWN, J. R., BECKENBACH, A. T. AND SMITH, M. J. 1993. Intraspecific DNA sequence variation of the mitochondrial control region of white sturgeon (Acipenser trans- 
montatus). Mol. Biol. Evol., 10, 326-341.

ESTES, R. D. 1991. The Behavior Guide to African Mammals. University of California Press, Berkeley.

FELSENSTEIN, J. 1985. Confidence limits on phylogenies: an approach using the bootstrap. Evolution, 39, 783-791.

FELSENSTEIN, J. 1993. PHYLIP version 3.5c (Phylogeny Inference Package). Distributed by the author. Department of Genetics, University of Washington, Seattle.

FRIES, R., EGGEN, A. AND WOMACK, J. E. 1993. The bovine genome map. Mamm. Genome, 4, 405-428.

Guo, s. w. AND thomson, E. A. 1992. Performing the exact test of Hardy-Weinberg proportions for multiple alleles. Biometrics, 48, 361-372.

HAMilton, A. C. 1982. Environmental History of East Africa. A Study of the Quaternary. Academic Press, London.

HORAI, S. AND HAYASAKA, K. 1990. Intraspecific nucleotide sequence differences in the major noncoding region of human mitochondrial DNA. Am. J. Hum. Genet., 46, $828-842$.

HUDSON, R. R., BOOS, D. D. AND KAPLAN, N. L. 1992. A statistical test for detecting geographic subdivision. Mol. Biol. Evol., 9, 138-151.

INNIS, M. A., GELFAND, D. H., SHINSKY, J. J. AND WHITE, T. J. 1990. PCR Protocols. Academic Press, San Diego, CA.

IRWIN, D. M., KOCHER, T. D. AND WILSON, A. C. 1991. Evolution of the cytochrome $b$ gene of mammals. J. Mol. Evol., 32, 128-136.

KARESH, w. B., SMITH, F. AND FRAZIER-TAYLOR, H. 1987. A remote method for obtaining skin biopsy samples. Conserv. Biol., 1, 261-262.

KINGDON, J. 1982. East African Mammals - An Atlas of Evolution in Africa, vol. 3C, University of Chicago Press, Chicago.

KOCHER, T. D., THOMAS, w. K., MEYER, A., EDWARDS, S. V., PÄÄBO, s., VILLABLANCA, F. X. AND WILSON, A. C. 1989. Dynamics of mitochondrial DNA evolution in animals: amplification with conserved primers. Proc. Natl. Acad. Sci. U.S.A., 86, 6196-6200.

MANLy, B. F. J. 1985. The Statistics of Natural Selection. Chapman and Hall, London.

MORIN, P. A., MOORE, J. J., CHAKRABORTY, R., JIN, L., GOODALL, J. AND WOODRUFF, D. s. 1994. Kin selection, social structure, gene flow, and the evolution of chimpanzees. Science, 265, 1193-1201.

NEI, M. 1987. Molecular Evolutionary Genetics. Columbia University Press, New York.
PALSBØLl, P. J., CLAPHAM, P. J., MATTILA, D. K., LARSEN, F., SEARS, R., SIEGISMUND, H. R., SIGURJONSSON, J., VASQUEZ, O. AND ARCTANDER, P. 1995. Distribution of mtDNA haplotypes in North Atlantic humpback whales: the influence of behaviour on population structure. Mar. Ecol. Prog. Ser., 116, 1-10.

PIERCY, R., SUlLIVAN, K. M., BENSON, N. AND GILL, P. 1993. The application of mitochondrial DNA typing to the study of white Caucasian genetic identification. Intl. J. Legal Med., 106, 85-90.

ROFF, D. A. AND BENTZEN, P. 1989. The statistical analysis of mitochondrial DNA polymorphisms: $\chi^{2}$ and the problems of small samples. Mol. Biol. Evol., 6, 539-545.

RON, M., YOFFE, O. AND WELLER, J. 1. 1993. Sequence variation in D-loop mtDNA of cow lineages selected for high and low maternal effects on milk production. Anim. Genet., 24, 183-186.

SACCONE, C., PESOLE, G. AND SBISA, E. 1991. The main regulatory region of mammalian mitochondrial DNA: structure-function model and evolutionary pattern. $J$. Mol. Evol., 33, 83-91.

SAMBROOK, J., FRITSCH, E. F. AND MANIATIS, T. 1989. Molecular Cloning. Cold Spring Harbor Laboratory Press, New York.

VILOTTE, J.-L., SOUlier, S., MERCIER, J. C., GAYE, P., HUE-DElahaie, D. AND FURET, J.-P. 1987. Complete nucleotide sequence of bovine $\alpha$-lactalbumin gene: comparison with its rat counterpart. Biochimie, 69, 609-620.

VIGILANT, L., STONEKING, M., HARPENDING, H., HAWKES, K. AND WILsON, A. C. 1991. African populations and the evolution of human mitochondrial DNA. Science, 253, 1503-1507.

WAYNE, R. K., LEHMAN, N., ALLARD, M. W. AND HONEYCUTT, R. L. 1992. Mitochondrial DNA variability of the gray wolf: genetic consequences of population decline and habitat fragmentation. Conserv. Biol., 6, 559-569.

WEIR, B. S AND COCKERHAM, C. C. 1984 . Estimating $F$-statistics for the analysis of population structure. Evolution, 38, 1358-1370.

WILSON, A. C., CANN, R. L., CARR, S. M., GEORGE, M., GYLLENSTEN, U. B., HELM-BYCHOWSKI, K. M., HIGUCHI, R. G., PAlumbi, s. R., PRAGER, E. M., SAGE, R. D. AND STONEKING, M. 1985. Mitochondrial DNA and two perspectives on evolutionarly genetics. Biol. J. Linn. Soc., 26, 375-400. 